\title{
Robust Exclusion Through Loyalty Discounts
}

\section{Citation}

Einer Elhauge and Abraham L. Wickelgren, Robust Exclusion Through Loyalty Discounts (Harvard John M. Olin Discussion Paper Series Discussion Paper No. 662, Jan. 2010 ).

\section{Published Version}

http://www.law.harvard.edu/programs/olin_center/papers/pdf/Elhauge_662.pdf

\section{Permanent link}

http://nrs.harvard.edu/urn-3:HUL.InstRepos:34816667

\section{Terms of Use}

This article was downloaded from Harvard University's DASH repository, and is made available under the terms and conditions applicable to Other Posted Material, as set forth at http:// nrs.harvard.edu/urn-3:HUL.InstRepos:dash.current.terms-of-use\#LAA

\section{Share Your Story}

The Harvard community has made this article openly available.

Please share how this access benefits you. Submit a story.

\section{Accessibility}




\section{HARVARD}

JOHN M. OLIN CENTER FOR LAW, ECONOMICS, AND BUSINESS

\section{ROBUST EXCLUSION THROUGH LOYALTY DISCOUNTS}

Einer Elhauge and Abraham L. Wickelgren

Discussion Paper No. 662

$01 / 2010$

Harvard Law School

Cambridge, MA 02138

This paper can be downloaded without charge from:

The Harvard John M. Olin Discussion Paper Series:

http://www.law.harvard.edu/programs/olin_center/

The Social Science Research Network Electronic Paper Collection:

http://ssrn.com/abstract=1544008 


\title{
Robust Exclusion Through Loyalty Discounts
}

\author{
Einer Elhauge and Abraham L. Wickelgren \\ Harvard University and University of Texas at Austin
}

January 2010 


\title{
Robust Exclusion through Loyalty Discounts
}

\author{
Einer Elhauge and Abraham L. Wickelgren \\ Harvard University and University of Texas at Austin
}

\begin{abstract}
We consider loyalty discounts whereby the seller promises to give buyers who commit to buy from it a lower price than the seller gives to uncommitted buyers. We show that an incumbent seller can use loyalty discounts to soften price competition between itself and a rival, which raises market prices to all buyers. Each individual buyer's agreement to a loyalty discount externalizes most of the harm of that individual agreement onto all the other buyers. The resulting externality among buyers makes it possible for an incumbent to induce buyers to sign these contracts even if they reduce buyer and total welfare. Thus, if the entrant cost advantage is not too large, we prove that with a sufficient number of buyers, there does not exist any equilibrium in which at least some buyers do not sign loyalty discount contracts, and there exists an equilibrium in which all buyers sign and the rival is foreclosed from entry. As a result, with a sufficient number of buyers, an incumbent can use loyalty discounts to increase its profit and decrease both buyer and total welfare. Further, the necessary number of buyers can be as few as three. These effects occur even in the absence of economies of scale in production and even if the buyers are not intermediaries who compete with each other in a downstream market.
\end{abstract}

JEL: C72, K21, L12, L40, L41, L42 


\section{Introduction}

Exclusionary agreements between suppliers and their customers have been a contentious issue in antitrust (both among lawyers and economists) at least since the 1970s. Some scholars associated with the Chicago School of antitrust analysis have argued that exclusionary contracts between a supplier and its buyers could never reduce welfare since they are the product of voluntary agreements. If the exclusion that resulted were inefficient, the supplier would have to pay the buyer more to agree to the contract than the added profit the supplier would gain from excluding a rival.

This argument prompted many game-theoretic analyses of exclusive contracts that demonstrated that there are situations in which a supplier could induce buyers to agree to a contract that excludes a rival, is profitable for the supplier, and reduces total welfare. The key to these analyses is the existence of an externality. When a buyer agrees to an exclusionary agreement, part of the loss from the agreement falls on a third party. For example, papers by Rasmusen et al. (1991) and Segal and Whinston (2000) assumed economies of scale in production created an externality among buyers that a supplier could exploit to generate profitable and inefficient exclusion. Simpson and Wickelgren (2007) assumed that competition among intermediate buyers created an externality on final consumers that a supplier could exploit to generate profitable and inefficient exclusion.

In this paper, we follow Elhauge (2009) in departing from the plain vanilla exclusive dealing contracts that have been considered in most prior work. Instead, we examine (the increasingly common) loyalty discount contracts. These are contracts in which a supplier promises to offer buyers who commit to buy only from it a specified discount off the price it offers to uncommitted buyers.

The proper economic analysis of loyalty discounts has been much disputed. Many scholars assume that loyalty discounts presumptively lower prices, and thus benefit consumer welfare in the short run, and assert that loyalty discounts cannot produce long-run harm to consumer welfare unless the discounts result in below-cost prices that drive out equally efficient rivals. ${ }^{1}$ On the other hand, loyalty discounts could easily function as exclusive dealing contracts, thereby having the potential to inefficiently exclude rivals and reduce competition as occurs in models of exclusive dealing. ${ }^{2}$

\footnotetext{
${ }^{1}$ Hovenkamp (2005), at 129, 132; Lambert (2005); Hovenkamp (2006).

${ }^{2}$ Rasmusen, et al., (1991); Segal \& Whinston, (2000); Tom, et al. (2000); Elhauge, pp. 284-92 (2003); Farrell, p. 476 (2005); Spector, pp. 99-101 (2005); Whinston, pp. 144-47, 166 (2006); Kaplow \& Shapiro, pp. 1203-1210 (2007); Elhauge, pp. 406-412 (2008).
} 
In this paper, we show that loyalty discounts can have very different anticompetitive effects from those found in plain vanilla exclusive contracts. In particular, loyalty discount contracts can raise prices above competitive levels in many situations in which plain vanilla exclusive contracts would not have this effect. For example, we show that loyalty discount contracts can be anticompetitive even if there are no economies of scale and buyers do not compete with each other.

The key difference between loyalty discount contracts and plain vanilla exclusive contracts are that loyalty discount contracts include not only buyer agreement to loyalty conditions, but also seller commitments to charge lower prices to buyers who agree to those loyalty conditions than to buyers who did not. This seller commitment reduces the seller's incentive to compete for buyers free of a loyalty agreement because lowering the price to free buyers requires lowering the price to loyal buyers who have already agreed to buy from the seller. This disincentive will limit the extent to which the seller lowers prices for free buyers, which means the sellers' rival has less incentive to lower prices as well, thus raising prices and harming consumer and total welfare. Buyers agree to these contracts, again, because of an externality. The externality is that when one buyer agrees to the loyalty discount contract all buyers suffer from the higher prices that result from less aggressive competition. Thus, an incumbent supplier need not compensate an individual buyer for the losses that all other buyers suffer (whether they have signed the loyalty discount contract or not). This enables an incumbent supplier to profitably induce buyers to sign loyalty discount contracts that lower overall welfare.

We prove that if the entrant's cost advantage is not too large, and the number of buyers is sufficient, then the incumbent can always offer a loyalty discount that, in every equilibrium, enough buyers accept that it raises prices and seller profits and reduces total welfare. We further prove that under these conditions there exists an equilibrium in which all buyers accept the loyalty discount, resulting in no rival entry and all the buyers purchasing from the incumbent at the monopoly price.

While we prove these results generally, we also analyze the linear demand case to get a sense of the magnitude of the problem. That is, we examine how many buyers it takes, given the relevant costs, for an incumbent seller to be able to use loyalty discounts to achieve profitable exclusion. We find that with as few as three buyers, loyalty discounts can profitably exclude rivals from all buyers as long as the entrant's cost advantage is less than $10 \%$ and the incumbent's costs are less than $28 \%$ of the choke price. If there are twenty buyers, the same result can be achieved as long as the incumbent's costs are less than $80 \%$ of the choke price. As we prove generally, there is also some welfare loss even if the rival is not completely excluded because of the softening of price 
competition.

The phenomenon identified here should be contrasted with price-matching or most favored nation clauses. Although such clauses also involve seller pricing commitments, they do not involve seller commitments to charge buyers who accepted loyalty discounts less than buyers who did not. Price-matching clauses instead involve seller commitments to match rival prices, ${ }^{3}$ whereas loyalty discounts have the opposite effect of discouraging sellers from matching rival prices for free buyers. Most-favored-nations clauses involve seller commitments to charge agreeing buyers no more than the seller charges other buyers, whereas loyalty discounts involve seller commitments to charge agreeing buyers less than the seller charges other buyers. Nor do either price-matching and mostfavored-nations clauses involve the sort of buyer loyalty commitments assumed here. Because the nature of the clauses differ, we find anticompetitive effects under very different conditions than are assumed in the literature on most-favored nation clauses. ${ }^{4}$

Our paper is most similar to Elhauge (2009), which also analyzes the anticompetitive effects of loyalty discounts. He also finds that an incumbent seller can use loyalty discount contracts to inefficiently foreclose a rival even in the absence of scale economies and even if buyers can breach these contracts while paying expectation damages. The most significant difference between our paper and Elhauge (2009) is that our paper finds that given a sufficient number of buyers (in our linear demand analysis, "sufficient" can mean three buyers), there does not exist an equilibrium in which all buyers reject a loyalty discount with buyer commitments. In contrast, in Elhauge (2009), there always exists an equilibrium in which loyalty discounts with buyer commitments have no effect because all buyers reject them. ${ }^{5}$ The main reason for the difference is that we analyze buyers' decision to accept loyalty discount contracts under the assumption of simultaneous pricing by the incumbent and rival following entry. While Elhauge (2009) considers simultaneous pricing (along with sequential pricing) in determining the equilibrium in the pricing subgame with a given fraction of buyers signing a loyalty discount contract, he does not analyze the simultaneous pricing case when determining whether buyers will accept or reject the loyalty discount contracts.

Another important difference is that our results are, in some ways, more general than

\footnotetext{
${ }^{3}$ See, e.g., Edlin (1997); Schnitzer (1994).

${ }^{4}$ Articles on most favored nations clauses have found anticompetitive effects because they assumed oligopolistic coordination, see Cooper (1986), or because they assumed a monopolist selling a durable good that might use such clauses to restrain competition by itself later in time, Butz (1990); Marx \& Shaffer (2004). None of those assumptions is necessary to show anticompetitive effects from loyalty discounts under the model offered here.

${ }^{5}$ For loyalty discounts without buyer commitments, Elhauge finds that the only equilibrium is buyer agreement, though the price effects are smaller than with buyer commitment. Elhauge, pp. 207-212 (2009).
} 
those in Elhauge (2009). That article considers only a linear demand model and does not allow the potential entrant to be more efficient than the incumbent seller. We prove our basic results without imposing any specific functional form on buyer demand, and we allow the rival's marginal cost to be strictly less than the incumbents. This formulation also allows us to explore, in our linear demand simulations, how much more efficient an entrant can be and still be foreclosed by loyalty discount contracts.

That said, Elhauge (2009) analyzes some cases that we do not consider. We do not consider cases in which either the rival or the incumbent act as a Stackleberg-leader in pricing. Furthermore, we assume that buyers who accept loyalty discounts make contractual commitments to buy only from the incumbent. ${ }^{6}$ Elhauge (2009) also considers the case in which the sellers offer of a loyalty discount does not bind the buyer. Lastly, unlike Elhauge (2009), we do not consider discounts based on partial loyalty. We assume loyalty discount contracts require the buyer to not purchase any goods from the rival.

Our paper is also related to the literature on exclusive dealing more generally. The challenge to the Chicago School's claim of that exclusive dealing could not be anticompetitive may have begun with Aghion and Bolton (1987). Since that time, there have been many models explaining situations in which plain vanilla exclusive dealing could be anticompetitive. ${ }^{7}$ As mentioned above, Rasmusen et al. (1991) and Segal and Whinston (2000) show that exclusive contracts can deter entry if there are many buyers and economies of scale in production. Simpson \& Wickelgren (2007) extend these models to find that, even without economies of scale, sellers can still get buyers to accept an anticompetitive exclusionary agreement in exchange for a small side payment if the buyers are intermediaries. ${ }^{8}$ In contrast, they find that (unlike what we find for loyalty discount contracts) if buyers are instead final consumers, then buyers will breach exclusionary agreements if a breach of those agreements is enforceable only by expectation damages.

Section 2 of the paper describes our model of loyalty discounts. In Section 3, we derive the duopoly pricing equilibrium. There we show that the pricing equilibrium must be in mixed strategies if the fraction of buyers who sign loyalty discount contracts is not too large. Section 3.1 derives

\footnotetext{
${ }^{6}$ As we explain below, allowing buyers to breach these contracts and pay expectation damages should not significantly affect our results.

${ }^{7}$ Other articles that challenge the Chicago School view include G. Frank Mathewson and Ralph A. Winter (1987), Kathryn E. Spier and Whinston (1995), B. Douglas Bernheim and Whinston (1998), and Zvika Neeman (1999). Robert Innes and Richard J. Sexton's (1994) article argues that the Chicago School claim that exclusive contracts are necessarily efficient can be resurrected if one allows all the players to form coalitions and price discrimination is prohibited.

${ }^{8}$ For a contrary view, see Fumagalli and Motta (2006).
} 
the mixed strategy equilibrium, while Section 3.2 examines some important properties of the equilibrium. In Section 4, we consider the buyers' decisions to sign loyalty discount contracts. Section 4.1 considers the linear demand case in order to get a sense of the magnitude of the anticompetitive effects. Section 5 concludes.

\section{Model}

An incumbent firm, $I$, produces a good at constant marginal cost, $c$. A potential entrant, $E$, can produce this same good at marginal cost, $c_{e}<c$. We assume, to highlight the anticompetitive effects of loyalty discounts, that $E$ incurs no fixed cost to enter the market. There are $N$ buyers for the good. Each buyer's demand function is given by $q(p), q^{\prime}<0, q^{\prime \prime} \leq 0$. Let $p^{m}=\arg \max _{p}(p-$ c) $q(p)$; that is, $p^{m}$ is $I$ 's profit-maximizing monopoly price. Let $p_{e}^{m}=\arg \max _{p}\left(p-c_{e}\right) q(p)$; that is, $p_{e}^{m}$ is $E$ 's profit-maximizing monopoly price.

Let $s(p)$ be a buyer's consumer surplus from buying $q(p)$ of the good at price $p$. $s(p)=$ $\int_{p}^{\infty} q(x) d x$. We make the following assumption about the maximum size of the entrant's cost advantage:

Assumption $(*)\left(p^{m}-c\right) q\left(p^{m}\right)>s\left(p_{e}^{m}\right)-s\left(p^{m}\right)$

Assumption $\left(^{*}\right)$ means that incumbent's profit from being a monopolist exceeds the increase in consumer surplus that results when buyers purchase at the entrant's monopoly price rather than the incumbents. Since the entrant's monopoly price depends on $c_{e}$, this simply requires that $c_{e}$ is not too far below $c$.

In period 1 , the incumbent offers a loyalty discount to buyers of the form $\{d, t\}$, where $d$ is the magnitude of the discount and $t$ is the transfer from $I$ to the buyer for agreeing to the loyalty discount. ${ }^{9}$ Buyers individually decide whether or not to accept this offer in period 1 . Those who accept must buy from the incumbent in period 3 and receive the discount. Then for any price $p_{f}$ that the incumbent offers to a buyer who did not accept the contract means that any buyer who did accept this contract in period 1 receives a price of $p_{f}-d$. Notice, this means that any buyer who did not agree to a loyalty discount in period 1 will not be able to receive the discounted price

\footnotetext{
${ }^{9}$ Notice, we do not allow $I$ to commit to a price at this time. This could be because the good is hard to describe in period 1. It could be because the cost of production is not precisely known in period 1 (our model could easily accomodate a common shock to production costs). Thus, agreeing to a loyalty discount simply means that the buyer receives a discount from the price offered to buyers who did not agree to this contract.
} 
from the incumbent in period 3. Let $\theta$ be the share of buyers who agree to the loyalty discount in period 1 .

In period $1.5, E$ decides whether to enter the market or not. In period $2, E$ (if active) and $I$ set prices simultaneously to free buyers of $p_{e}, p_{f}$ respectively. I's price to buyers who accept the contract is $p_{f}-d$. If $\theta=0$ or $d=0$, then there are, in effect, no loyalty discounts. In that case, because $E$ and $I$ produce identical products, we have the standard Bertrand result that $E$ captures the entire market at a price of $p_{e}=c$. In period 3 , buyers make purchase decisions.

First, suppose that $E$ enters in period 1.5 and $I$ and $E$ set prices $p_{f}$ and $p_{e}$ respectively in period 2. Then, in period 3 , if $p_{e} \leq p_{f}$, then only free buyers purchase from $E$, and committed buyers purchase entirely from $I{ }^{10}$ Thus, $I$ 's profit is $\theta\left(p_{f}-d-c\right) q\left(p_{f}-d\right)$, while $E$ 's profit is $(1-\theta)\left(p_{e}-c_{e}\right) q\left(p_{e}\right)$. If $p_{e}>p_{f}$, then all buyers purchase from $I$. Thus, I's profit is $\theta\left(p_{f}-d-\right.$ c) $q\left(p_{f}-d\right)+(1-\theta)\left(p_{f}-c\right) q\left(p_{f}\right)$ while $E$ 's profit is zero.

\section{Duopoly Pricing Equilibrium}

The next step is to determine the equilibrium for the period 2 pricing subgame given entry. To do so, first notice that if $\theta$ is large enough (and $d>0$ or $c_{e}<c$ ), then there is a unique purestrategy equilibrium in which both firms charge their monopoly prices to their respective markets $\left(p_{f}=p^{m}+d\right.$ and $\left.p_{e}=p_{e}^{m}\right)$ and all committed buyers purchase from $I$ at $p^{m}$ and all free buyers purchase from $E$ at $p_{e}^{m}$. $E$ has no incentive to deviate since it is maximizing its profits. $I$ could undercut $E$ only by charging $p_{f}=p_{e}^{m}-\varepsilon$ for some $\varepsilon>0$. If either $d>0$ or $c_{e}<c$, this implies that the price to committed buyers, $p_{f}-d<p^{m}$. For large enough $\theta$, this reduction in profits from committed buyers outweighs the gain in profits from stealing the free buyers from $E$. Thus, this is Nash equilibrium if $\theta$ is large enough. To show that the equilibrium is unique, imagine there is another equilibrium with $p_{f} \neq p^{m}+d$. If $p_{f}>p^{m}+d$, then $I$ could easily increase its profits by reducing $p_{f}$ to $p^{m}+d$. If $p_{f}<p^{m}+d$, even if this allowed $I$ to capture the entire market, the same argument as above shows that for $\theta$ large enough, $I$ can increase its profits by setting $p_{f}=p^{m}+d$ and only selling to committed buyers. Thus, for large enough $\theta$, any equilibrium must have $p_{f}=p^{m}+d$, and $E$ 's unique best response to this is $p_{e}=p_{e}^{m}$.

\footnotetext{
${ }^{10}$ Notice, we make the standard tie-breaking assumption that if both firms charge the identical price, then buyers buy from the lower cost firm ( $E$ in this case). This assumption makes the analysis of the standard Bertrand equilibrium less cumbersome since the equilibrium price is simply the cost of the higher cost firm rather than some epsilon below that level.
} 
To determine how large $\theta$ must be to have both firms charging their monopoly prices, notice that $I$ will only attempt to capture the entire market if it can do so at a price $p_{f}$ such that $\theta\left(p_{f}-d-c\right) q\left(p_{f}-d\right)+(1-\theta)\left(p_{f}-c\right) q\left(p_{f}\right)>\theta\left(p^{m}-c\right) q\left(p^{m}\right)$. Let $\bar{\theta}$ be defined implicitly by

$$
\bar{\theta}\left(p_{e}^{m}-d-c\right) q\left(p_{e}^{m}-d\right)+(1-\bar{\theta})\left(p_{e}^{m}-c\right) q\left(p_{e}^{m}\right)=\bar{\theta}\left(p^{m}-c\right) q\left(p^{m}\right)
$$

For $\theta \geq \bar{\theta}$, the argument in the last paragraph establishes that there is a unique pure-strategy equilibrium in which $I$ and $E$ charge monopoly prices $\left(p^{m}\right.$ and $p_{e}^{m}$, respectively) to committed and

free buyers respectively. For $\theta<\bar{\theta}$, this equilibrium does not exist since $I$ could increase its profits charging $p_{f}=p_{e}^{m}-\varepsilon$ so long as $E$ sets $p_{e}=p_{e}^{m}$.

For $\theta<\bar{\theta}$, there is no pure strategy equilibrium. To see this, define $p_{e}^{*}$ implicitly by:

$$
\left.\theta\left(p_{e}^{*}-d-c\right) q\left(p_{e}^{*}-d\right)+(1-\theta)\left(p_{e}^{*}-c\right) q p_{e}^{*}\right)=\theta\left(p^{m}-c\right) q\left(p^{m}\right)
$$

Obviously, $p_{e}^{*}$ is a function of $\theta$. For $p_{e}>p_{e}^{*}$, I's best response is to choose $p_{f}=p_{e}-\varepsilon$, while for $p_{e} \leq p_{e}^{*}$, I's best response is to choose $p_{f}=p^{m}+d$. But if $p_{f}=p_{e}-\varepsilon$, then $E$ 's best response is not to charge $p_{e}$ (since that yields zero profit), but to charge $p_{f}$ (since we have assumed that all sales go to $E$ if both charge the same price). If $p_{f}=p^{m}+d$, then $E$ 's best response is to charge $p_{e}^{m}>p_{e}^{*}$ for $\theta<\bar{\theta}$. Thus, there is no possible equilibrium in pure strategies. We have now proved the following lemma.

Lemma 1 For $\theta \geq \bar{\theta}$, the unique pure-strategy equilibrium in the period 2 pricing subgame given entry by $E$ is for $I$ to set $p_{f}=p^{m}+d$ and $E$ to set $p_{e}=p_{e}^{m}$. Then I sells to committed buyers at $p^{m}$ and $E$ sells to free buyers at $p_{e}^{m}$. For $\theta<\bar{\theta}$, there is no pure-strategy equilibrium in the period 2 subgame if $E$ has entered.

Thus, if the fraction of buyers who have committed to buy from the incumbent is large, then all buyers will effectively face only one seller and pay monopoly prices. If fewer buyers have signed the loyalty discount, however, the incumbent and the entrant must play a mixed strategy equilibrium

\subsection{Deriving the Mixed Strategy Equilibrium}

The next step is the characterize the mixed strategy equilibrium that exists for smaller values of $\theta$. Let $F(p)$ denote the cumulative distribution function of the incumbent's price to free buyers and let $f$ be the associated probability density function. Let $F_{e}(p)$ denote the cumulative distribution 
function of the entrant's price with associated density function $f_{e}$. The incumbent's profit from a price of $p_{f}$ to free buyers is:

$$
\theta\left(p_{f}-d-c\right) q\left(p_{f}-d\right)+(1-\theta)\left(1-F_{e}\left(p_{f}\right)\right)\left(p_{f}-c\right) q\left(p_{f}\right)
$$

The incumbent sells to all committed buyers at a price of $p_{f}-d$. It also sells to the $1-\theta$ free buyers if the entrant's price is greater than $p_{f}$. This occurs with probability $1-F_{e}\left(p_{f}\right)$.

For the incumbent to play a mixed strategy, it must be that its profit is the same for all prices in the support of $f$. This implies that (3) must be the same for all $p_{f}$ (that is, the derivative with respect to $p_{f}$ must be zero for all $p_{f}$ in the support of $f$ ). Thus, $F_{e}$ must satisfy:

$\theta\left[q\left(p_{f}-d\right)+\left(p_{f}-d-c\right) q^{\prime}\left(p_{f}-d\right)\right]+(1-\theta)\left[\left(1-F_{e}\left(p_{f}\right)\right) q\left(p_{f}\right)+\left(1-F_{e}\left(p_{f}\right)\right)\left(p_{f}-c\right) q^{\prime}\left(p_{f}\right)-f_{e}\left(p_{f}\right)\left(p_{f}-c\right) q\left(p_{f}\right)\right]=0$

To solve this differential equation, we need an appropriate boundary condition. The following lemma provides this condition.

Lemma 2 In any mixed strategy equilibrium, I chooses $p_{f}=p^{m}+d$ with positive probability.

Proof. Since $E$ will never charge above $p_{e}^{m}, I$ will never choose a price between $p_{e}^{m}$ and $p^{m}$, because this would result in zero sales to uncommitted buyers and a price to committed buyers that is less than the $p^{m}$ that would maximize profits if $I$ makes no uncommitted sales. That is, if $I$ ever charges a price above $p_{e}^{m}$, that price must be $p^{m}+d$. Thus, if $I$ never charges $p^{m}+d$, then $I$ always prices below $p_{e}^{m}$. E's maximum price must never exceed $I$ 's maximum price since $E$ would have zero profit if it charged such a price. But, if $I$ 's maximum price exceeds E's maximum price, then $I$ will have no sales to uncommitted buyers, in which case it is better off charging $p^{m}+d$. Q.E.D.

If $I$ chooses $p^{m}+d$ with positive probability, its profits from any price it chooses must be $\theta\left(p^{m}-c\right) q\left(p^{m}\right)$. Using this condition, we obtain the following unique solution the the differential equation (4):

$$
F_{e}(p)=1-\theta \frac{\left(p^{m}-c\right) q\left(p^{m}\right)-(p-d-c) q(p-d)}{(1-\theta)(p-c) q(p)}
$$

Notice, however, that using (5), the entrant's distribution function doesn't become one until a price of $p^{m}+d$. But, $E$ has no reason to ever charge above $p_{e}^{m}$. Thus, there is an atom in the entrant's pricing distribution at $p_{e}^{m}$ of $\theta \frac{\left(p^{m}-c\right) q\left(p^{m}\right)-\left(p_{e}^{m}-d-c\right) q\left(p_{e}^{m}-d\right)}{(1-\theta)\left(p_{e}^{m}-c\right) q\left(p_{e}^{m}\right)}$. Thus, abusing notation 
slightly, we write the entrant's pricing distribution function as:

$$
F_{e}(p)=\left\{\begin{array}{l}
1-\theta \frac{\left(p^{m}-c\right) q\left(p^{m}\right)-(p-d-c) q(p-d)}{(1-\theta)(p-c) q(p)} \text { for } p<p_{e}^{m} \\
1 \quad \text { for } p \geq p_{e}^{m}
\end{array}\right.
$$

To determine the incumbent's pricing distribution function, we look at the entrant's profit from charging a price of $p_{e}$ :

$$
(1-\theta)\left(1-F\left(p_{e}\right)\right)\left(p_{e}-c_{e}\right) q\left(p_{e}\right)
$$

The entrant only sells to the $1-\theta$ buyers who have not committed to buy from the incumbent and receive the loyalty discount. It only sells to those buyers if the incumbent's price to free buyers is higher than the entrant's price. This occurs with probability $1-F\left(p_{e}\right)$. For the entrant to play a mixed strategy, it must receive the same profits for all prices in the support of $F_{e}$, which implies the following condition on those prices:

$$
(1-\theta)\left[\left(1-F\left(p_{e}\right)\right) q\left(p_{e}\right)+\left(1-F\left(p_{e}\right)\right)\left(p_{e}-c_{e}\right) q^{\prime}\left(p_{e}\right)-f\left(p_{e}\right)\left(p_{e}-c_{e}\right) q\left(p_{e}\right)\right]=0
$$

The appropriate boundary condition for this differential equation is given by noting that there is a minimum price in $I$ 's distribution, $p_{0}$, defined implicitly by:

$$
\theta\left(p_{0}-d-c\right) q\left(p_{0}-d\right)+(1-\theta)\left(p_{0}-c\right) q\left(p_{0}\right)=\theta\left(p^{m}-c\right) q\left(p^{m}\right)
$$

That is, $p_{0}$ is price for which $I$ earns as much profit from capturing the entire market at a price (and charging free buyers $p_{0}$ and committed buyers $p_{0}-d$ ) as it would from only selling to committed buyers at the monopoly price. I certainly would never charge less than $p_{0}$ to free buyers. The minimum of its pricing support cannot exceed this level since if it did, then $E$ would price above $p_{0}$ with probability one. In that case, $I$ could increase its profits by charging just under $E$ 's minimum price but above $p_{0}$ since then it would capture the entire market while charging free buyers greater than $p_{0}$. Using (8), the unique solution to (7) is:

$$
F(p)=1-\frac{\left(p_{0}-c_{e}\right) q\left(p_{0}\right)}{\left(p-c_{e}\right) q(p)}
$$

Once again, notice that using (9), $I$ has a positive probability of pricing at any price above $p_{e}^{m}$ when we know that the only price above $p_{e}^{m}$ that $I$ ever charges is $p^{m}+d$. Thus, there is an atom 
at $p^{m}+d$ of $\frac{\left(p_{0}-c_{e}\right) q\left(p_{0}\right)}{\left(p_{e}^{m}-c_{e}\right) q\left(p_{e}^{m}\right)}$, so that the actual distribution function for $I$ 's price is given by:

$$
F(p)=\left\{\begin{array}{cc}
1-\frac{\left(p_{0}-c_{e}\right) q\left(p_{0}\right)}{\left(p-c_{e}\right) q(p)} \text { for } p<p_{e}^{m} \\
1-\frac{\left(p_{0}-c_{e}\right) q\left(p_{0}\right)}{\left(p_{e}^{m}-c_{e}\right) q\left(p_{e}^{m}\right)} \text { for } p \in\left[p_{e}^{m}, p^{m}+d\right) \\
1 \quad \text { for } p \geq p^{m}+d
\end{array}\right.
$$

\subsection{Properties of the Mixed Strategy Equilibrium}

Given the fraction of buyers, $\theta$, who sign the loyalty discount contract and the magnitude of the discount, $d$, the pricing equilibrium is given by equations (6) and (10). Using these equations, we can derive the effect of the entrant's and incumbent's costs, the fraction of signers, and the magnitude of the discount on the pricing equilibrium. The first proposition does that.

Proposition 1 As long as the entrant's innovation is non-drastic, $p_{e}^{m}>c$, for any fixed $\theta \in(0,1)$, $d>0$ and $c_{e}<c:$ (i) An increase in $c_{e}$ to $c_{e}^{\prime}$ has no affect on the entrant's pricing distribution below $p_{e}^{m}$ but creates a positive probability of prices $p_{e} \in\left(p_{e}^{m}, p_{e}^{\prime m}\right]$. An increase in $c_{e}$ to $c_{e}^{\prime}$ increases the probability that the incumbent chooses a price lower than any given level $p<p_{e}^{m}$ but creates a positive probability of prices $p \in\left(p_{e}^{m}, p_{e}^{\prime m}\right]$. (ii) An increase in $c$ reduces the probability that both the entrant and the incumbent choose a price lower than any given level $p<p_{e}^{m}$. (iii) An increase in $\theta$ reduces the probability that both the entrant and the incumbent choose a price lower than any given level $p<p_{e}^{m}$. (iv) An increase in d reduces the probability that both the entrant and the incumbent choose a price lower than any given level $p<p_{e}^{m}$.

Proof. (i) Inspection of (5) makes it clear that it does not depend on $c_{e}$. Since increasing $c_{e}$ increases $p_{e}^{m}$, however, the atom at $p_{e}^{m}$ is now spread out between $\left[p_{e}^{m}, p_{e}^{\prime m}\right]$. $p_{0}$ is also not affected by $c_{e}$ (see (8)). Differentiating (9) with respect to $c_{e}$ gives $\frac{\left(p-p_{0}\right) q\left(p_{0}\right)}{\left(p-c_{e}\right)^{2} q(p)}>0$. Thus, for any $p<p_{e}^{m}$, the probability that the incumbent charges a price less than $p$ is increasing in $c_{e}$ for $p<p_{e}^{m}$. There is a new atom at $p_{e}^{\prime m}$ and positive probability up to $p_{e}^{\prime m}$. (ii) Differentiating (6) with respect to $c$ gives $-\theta \frac{\left(p^{m}-p\right) q\left(p^{m}\right)+d q(p-d)+\left(d p^{m} / d c\right)\left[q\left(p^{m}\right)+\left(p^{m}-c\right) q^{\prime}\left(p^{m}\right)\right]}{(1-\theta)(p-c)^{2} q(p)}<0$. This is negative since the term in square brackets in the numerator is zero because $p^{m}$ maximizes profits and $p^{m}>p$ and $d>0$. $c$ only affects the incumbent's pricing distribution, (10), through its effect on $p_{0}$. Since $p_{0}<p^{m}$, increasing $p_{0}$ decreases $F(p)$ for any $p<p_{e}^{m}$. Totally differentiating (8) with respect to $c$ and solving for $\frac{d p_{0}}{d c}$ gives $\frac{d p_{0}}{d c}=\frac{(1-\theta) q\left(p_{0}\right)+\theta\left(q\left(p_{0}-d\right)-q\left(p^{m}\right)\right)+\theta\left(d p^{m} / d c\right)\left[q\left(p^{m}\right)+\left(p^{m}-c\right) q^{\prime}\left(p^{m}\right)\right]}{(1-\theta)\left[q\left(p_{0}\right)+\left(p_{0}-c\right) q^{\prime}\left(p_{0}\right)\right]+\theta\left[q\left(p_{0}-d\right)+\left(p_{0}-d-c\right) q^{\prime}\left(p_{0}-d\right)\right]}>0$. This is positive since $p_{0}<p^{m}, d>$ 0 , and $q\left(p^{m}\right)+\left(p^{m}-c\right) q^{\prime}\left(p^{m}\right)=0$. So, increasing $c$ increases $p_{0}$ which reduces $F(p)$ for any $p<p_{e}^{m}$. (iii) $\theta$ only affects the incumbent's pricing through its effect on $p_{0}$. Totally differentiating (8) with 
respect to $\theta$ and solving for $\frac{d p_{0}}{d \theta}$ gives $\frac{d p_{0}}{d \theta}=\frac{\left(p_{0}-c\right) q\left(p_{0}\right)+\left(p^{m}-c\right) q\left(p^{m}\right)-\left(p_{0}-d-c\right) q\left(p_{0}-d\right)}{(1-\theta)\left[q\left(p_{0}\right)+\left(p_{0}-c\right) q^{\prime}\left(p_{0}\right)\right]+\theta\left[q\left(p_{0}-d\right)+\left(p_{0}-d-c\right) q^{\prime}\left(p_{0}-d\right)\right]}>0$. So, increasing $\theta$ increases $p_{0}$ which reduces $F(p)$ for any $p<p_{e}^{m}$. Differentiating (6) with respect to $\theta$ gives $-\theta \frac{\left(p^{m}-c\right) q\left(p^{m}\right)-(p-d-c) q(p-d)}{(1-\theta)(p-c)^{2} q(p)}<0$. So, increasing $\theta$ reduces the probability that the entrant chooses a price below any given level $p<p_{e}^{m}$. (iv) $d$ only affects the incumbent's pricing through its effect on $p_{0}$. Totally differentiating (8) with respect to $d$ and solving for $\frac{d p_{0}}{d d}$ gives $\frac{d p_{0}}{d d}=\frac{\theta\left[q\left(p_{0}-d\right)+\left(p_{0}-d-c\right) q^{\prime}\left(p_{0}-d\right)\right]}{(1-\theta)\left[q\left(p_{0}\right)+\left(p_{0}-c\right) q^{\prime}\left(p_{0}\right)\right]+\theta\left[q\left(p_{0}-d\right)+\left(p_{0}-d-c\right) q^{\prime}\left(p_{0}-d\right)\right]}>0$. So, increasing $d$ increases $p_{0}$ which reduces $F(p)$ for any $p<p_{e}^{m}$. Differentiating (6) with respect to $d$ gives $-\theta \frac{q(p-d)+(p-d-c) q^{\prime}(p-d)}{(1-\theta)(p-c) q(p)}<0$. So, increasing $d$ reduces the probability that the entrant chooses a price below any given level $p<p_{e}^{m}$. Q.E.D.

Because we have a mixed strategy equilibrium in which the entrant's price distribution is such that the incumbent is indifferent between a range of prices, changes in the entrant's costs do not affect its pricing distribution since they do not directly affect the incumbent's profit. Increasing the entrant's costs, however, does make the incumbent price more aggressively. This is necessary to ensure the higher cost entrant does not strictly prefer prices at the high end of its distribution. The effect of increasing the incumbent's cost is very different because the incumbent has the option of selling to its captive buyers at its monopoly price. Thus, the entrant's price distribution must be such that the incumbent is indifferent between ceding the free buyers to the entrant and competing for them. When the incumbent's cost increase, it becomes less profitable for it to compete for free buyers at a given distribution of entrant prices, thus, the entrant must price less aggressively to maintain the incumbent's mixed strategy. The incumbent's minimum profitable price to sell to free buyers increases with its costs, and this makes its entire price distribution less aggressive. Not surprisingly, increasing the share of captive buyers makes the incumbent less aggressive in capturing free buyers, and this, in turn, makes the entrant less aggressive as well. A larger discount has the same effect because it makes it more costly for the incumbent to compete for free buyers by reducing its profit from captive buyers. Of course, when considering the effect of costs on pricing, it is important to note that this takes as given the period 1 loyalty discount decisions. But, since, for example, higher entrant costs make the incumbent price more aggressively, that should make signing the loyalty discount contract more attractive. We turn to the decision to sign or reject loyalty discount contracts next. 


\section{Buyer Loyalty Discount Decisions}

Now that we have established the distribution of prices buyers will face given entry, we can determine buyer's optimal decisions regarding acceptance of the incumbent's loyalty discount offers. Proposition 2 gives our main result.

Proposition 2 (A) If $N$, the number of buyers, is sufficiently large and $c-c_{E}$ is small enough, then there exists $a d \geq 0$ and $t \geq 0$ such that the incumbent can profitably offer buyers a loyalty discount contract of $\{d, t\}$ such that in any equilibrium in the subgame following this offer some buyers accept this offer and prices exceed what they would have been absent loyalty discounts.

(B) There exists an $\bar{N}_{B}$ such that if the number of buyers exceeds $\bar{N}_{B}$ and Assumption (*) holds, then there exists a $d \geq 0$ and $t \geq 0$ such that the incumbent can profitably offer buyers a loyalty discount contract of $\{d, t\}$ such that there exists a subgame perfect equilibrium in which all buyers accept the incumbent's offer, the entrant does not enter, and all buyers purchase from the incumbent at $p^{m}$.

Proof. First, we prove (B), that there exists an equilibrium in which all buyer's accept a loyalty discount contract that increases the incumbent's profit. A buyer's payoff from accepting a loyalty discount contract depends on its expectations about what other buyers will do. If it expects even after rejecting this contract that $\theta \geq \bar{\theta}$, then it will pay $p^{m}$ if it accepts the contract and $p_{e}^{m}$ if it rejects. Because we have assumed that $\left(p^{m}-c\right) q\left(p^{m}\right)>s\left(p_{e}^{m}\right)-s\left(p^{m}\right)$, there exists a $t \in\left(\left[s\left(p_{e}^{m}\right)-s\left(p^{m}\right),\left(p^{m}-c\right) q\left(p^{m}\right)\right]\right.$ such that all buyers will accept $\{d, t\}$ for such a $t$ (and any $d \geq 0$ ) if they believe enough other buyers will (such that $\theta \geq \bar{\theta}$ even if they reject). Since all buyers accept the contract, the incumbent can profitably offer this contract with $t \leq\left(p^{m}-c\right) q\left(p^{m}\right)$. As long as either $d>0$ or $c_{E}<c, \bar{\theta}<1$. This means that for sufficiently large $N,(N-1) / N>\bar{\theta}$. Thus, there will be an equilibrium in which all buyers accept this loyalty discount contract. Since all buyers accept, the entrant cannot profitably enter and the incumbent will charge all buyers $p^{m}$.

Next, we prove (A). That is, we show that the incumbent can profitably guarantee that there does not exist an equilibrium in which all buyers reject the loyalty discount contract. To do so, first notice that if all buyers reject the loyalty discount contract, then each buyer can purchase the good at $c$, the incumbent's cost, and obtain surplus of $s(c)$. If $N-1$ buyers reject the loyalty discount contract, then the one committed buyer can purchase the good only from the incumbent 
at $p_{f}-d$. Thus, this buyer's surplus depends on the distribution of the incumbent's price to free buyers, $p_{f}$, when $N-1$ buyers are not committed. This distribution depends on the number of committed buyers because $p_{0}$, determined by equation (8), is a function of $\theta$. Notice that as $\theta \rightarrow 0$, $p_{0} \rightarrow c$. Thus, by making $N$ large enough, we can make $p_{0}$ arbitrarily close to $c$.

Equation (10) tells us that the probability that $I$ charges a price above $p$ is $\frac{\left(p_{0}-c_{e}\right) q\left(p_{0}\right)}{\left(p-c_{e}\right) q(p)}$ (as long as $p<p_{e}^{m}$ ). Since we can make $p_{0}$ arbitrarily close to $c$, this will be arbitrarily close to zero for $p>c$ if $c_{e}=c$. That is, if the entrant has no cost advantage, as $N$ gets very large, the incumbent will charge a price arbitrarily close to $c$ to probability arbitrarily close to one. This means that even if $d=0$, the committed buyer will obtain a consumer surplus of arbitrarily close to $s(c)$, the same surplus she would obtain if she were free. Thus, if $c_{E}=c$, if a buyer thinks all other buyers will not sign, this buyer can be induced to sign a loyalty discount contract for an arbitrarily small amount. Recall, however, from the construction of the mixed strategy equilibrium, that the incumbent's expected profit from having this buyer sign the loyalty discount contract is still $\left(p^{m}-c\right) q\left(p^{m}\right)>>0$. Furthermore, since $F$ is continuous in $c_{E}$, for $c-c_{E}$ small enough, the buyer's expected surplus loss from signing the loyalty discount contract will remain less than $\left(p^{m}-c\right) q\left(p^{m}\right)$. Thus, as long as $c-c_{E}$ is small enough, the incumbent will always offer a payment large enough to induce one buyer to sign the loyalty discount contract. Hence, there will never be an equilibrium in which all buyers are free. As long as some buyers are committed, equations (10) and (6) indicate that prices will exceed $c$ with positive probability. Q.E.D.

Proposition 2 says that if the incumbent can offer loyalty discounts, then if the entrant's cost advantage is not too large and there are many buyers, there will never be an equilibrium in which all buyers reject these loyalty discounts. This occurs even though these loyalty discounts raise prices above the competitive level and make all buyers worse off. While prior results (Rasmusen et al. 1991, Segal and Whinston 2000) on basic exclusive dealing contracts have established that these contracts can create an equilibrium in which all buyers also sign exclusive dealing contracts and buyers pay supra-competitive prices as a result, Proposition 2 demonstrates that loyalty discount contracts are more damaging for two reasons. First, with basic exclusive dealing contracts, when buyers are offered exclusive contracts simultaneously, there is always an equilibrium in which every buyer rejects the contract and all buyers pay competitive prices. In fact, this is the unique perfectly coalition proof Nash equilibrium. In contrast, Proposition 2 shows that with loyalty discount contracts, such an equilibrium may not exist. With enough buyers, if the incumbent's costs are not too far above the entrants, then some buyers must always sign the loyalty discount contracts, 
resulting in all buyers paying supra-competitive prices. Second, the prior results on exclusive dealing, at least when buyers are final consumers or independent monopolists, only demonstrated anticompetitive results in the presence of economies of scale. Proposition 2 shows that loyalty discounts will have anticompetitive results even with constant returns to scale.

The reason that loyalty discounts have such robust anticompetitive effects is that they create a negative externality among buyers even without economies of scale. Every buyer who signs a loyalty discount contract changes both the incumbent and the entrant's pricing distribution by making it less aggressive. The more buyers who are committed to buy from the incumbent, the more attractive it is for the incumbent simply to exploit those buyers, which makes it less aggressive in trying to lower its price to attract free buyers. This, in turn, makes the entrant less aggressive in attracting free buyers. Thus, a buyer who signs a loyalty discount contract passes some of the social loss from doing so onto other buyers. This makes it possible to induce buyers to sign even though there is dead weight loss associated with these contracts.

Once enough buyers are expected to sign these contracts, the market is effectively segmented: the incumbent only competes for committed buyers and the entrant only competes for free buyers. In this case, as long as the entrant's cost advantage is small enough to satisfy Assumption (*), the incumbent can always compensate buyers enough so that all will sign the contract. Thus, there is always an equilibrium in which all buyers sign the loyalty discount contracts. If fewer buyers are expected to sign, there may be greater losses for buyers from being committed to buy from the incumbent. However, Proposition 1 shows that, at least for the first buyer who signs the loyalty discount contract, this loss may still be less than the incumbent's profit. It is possible, however, that there could be an intermediate equilibrium in which some number of buyers between one and $N$ sign the loyalty discount contract. This would not result in complete exclusion, but it does lead to prices that are above the competitive level with positive probability. That said, as we show in the next subsection, in the case of linear demand, if the entrant's cost advantage is small enough then the equilibrium in which all buyers sign the loyalty discount contracts is unique.

Proposition 2 says that anticompetitive effects are guaranteed if there are enough buyers and the entrant's cost advantage is small enough. Even with a general demand function, we can go further to say that the effect of the entrant's cost and the number of buyers on the ability of the incumbent to get one signer is monotonic. Proposition 3 describes the result.

Proposition 3 (i) If, for any given $c$ and $N$, the incumbent can profitably induce at least one buyer to sign a loyalty discount contract in period 1 if the entrant's costs are $\bar{c}_{e}$, then the 
incumbent can induce at least one buyer to sign a loyalty discount contract in period 1 if the entrant's costs are $c_{e}>\bar{c}_{e}$. (ii) If, for any given $c$ and $c_{e}$, the incumbent can profitably induce at least one buyer to sign a loyalty discount contract in period 1 if the there are $\bar{N}$ buyers, then the incumbent can induce at least one buyer to sign a loyalty discount contract in period 1 if there are $N>\bar{N}$ buyers.

Proof. If all buyers reject the loyalty discount contract, then all buyers buy at $c$. If one buyer accepts the loyalty discount contract, then it pays a price of $p-d$ where $p$ is distributed according to (10). The consumer surplus associated with any given price is clearly decreasing in price. (i) Expected consumer surplus from signing a loyalty discount contract is $\int_{p_{0}}^{p_{e}^{m}} s(p-d) f(p) d p+$ $\frac{\left(p_{0}-c_{e}\right) q\left(p_{0}\right)}{\left(p_{e}^{m}-c_{e}\right) q\left(p_{e}^{m}\right)} s\left(p^{m}\right)$. Differentiating this with respect to $c_{e}$ (and realizing that $p_{e}^{m}$ depends on $c_{e}$ ) gives the following:

$$
\int_{p_{0}}^{p_{e}^{m}} s(p-d) \frac{d f(p)}{d c_{e}} d p+f\left(p_{e}^{m}\right) s\left(p_{e}^{m}-d\right) \frac{d p_{e}^{m}}{d c_{e}}-\frac{\left(p_{e}^{m}-p_{0}\right) q\left(p_{0}\right)}{\left(p_{e}^{m}-c_{e}\right)^{2} q\left(p_{e}^{m}\right)} s\left(p^{m}\right)
$$

The last term does not contain a $\frac{d p_{e}^{m}}{d c_{e}}$ term since the term multiplying it is zero by the envelope theorem. Differentiating (9) with respect to $p$ and evaluating at $p_{e}^{m}$ gives $f\left(p_{e}^{m}\right)=$ $\frac{\left(p_{0}-c_{e}\right) q\left(p_{0}\right)\left(q\left(p_{e}^{m}\right)+\left(p_{e}^{m}-c_{e}\right) q^{\prime}\left(p_{e}^{m}\right)\right)}{\left(p_{e}^{m}-c_{e}\right)^{2} q\left(p_{e}^{m}\right)^{2}}=0$ since $q\left(p_{e}^{m}\right)+\left(p_{e}^{m}-c_{e}\right) q^{\prime}\left(p_{e}^{m}\right)=0$ by definition of $p_{e}^{m}$. Because surplus is decreasing in price, the first term is greater than $s\left(p_{e}^{m}-d\right) \frac{d F\left(p_{e}^{m}\right)}{d c_{e}}$ where $F\left(p_{e}^{m}\right)$ is given by (9) rather than (10). Thus, effect of $c_{e}$ on expected surplus from signing is greater than $\frac{\left(p_{e}^{m}-p_{0}\right) q\left(p_{0}\right)}{\left(p_{e}^{m}-c_{e}\right)^{2} q\left(p_{e}^{m}\right)}\left(s\left(p_{e}^{m}-d\right)-s\left(p^{m}\right)\right)>0\left(\right.$ since $\left.\frac{d F\left(p_{e}^{m}\right)}{d c_{e}}=\frac{\left(p_{e}^{m}-p_{0}\right) q\left(p_{0}\right)}{\left(p_{e}^{m}-c_{e}\right)^{2} q\left(p_{e}^{m}\right)}\right)$. The consumer surplus from rejecting is clearly independent of $c_{e}$ since the price is fixed at $c$. Thus, the expected loss in consumer surplus from signing the loyalty discount contract is decreasing in $c_{e}$. Thus, the amount necessary to compensate one buyer for signing the loyalty discount is decreasing in $c_{e}$. Because the incumbent plays a mixed pricing strategy which includes in its support charging the monopoly price to all signing buyers, its profit is simply the monopoly profit per buyer times the number of signing buyers. Thus, the incumbent will pay up to the monopoly profit per buyer to induce buyers to sign. So, if the amount necessary to compensate one buyer for signing the loyalty discount contract is less than the monopoly profit per buyer at $\bar{c}_{e}$, then it is less for any $c_{e}>\bar{c}_{e}$. (ii) Since Proposition 1(iii) says that the incumbent's distribution function is decreasing in $\theta$, this implies that the expected consumer surplus from being the only singer is increasing in $N$ (because $\theta=1 / N$ if a buyer is the only signer). The consumer surplus from rejecting is clearly independent of $N$ since the price is fixed at $c$. Thus, the expected loss in consumer surplus from signing the loyalty 
discount contract is decreasing in $N$. Thus, the amount necessary to compensate one buyer for signing the loyalty discount is decreasing in $N$. So, if the amount necessary to compensate one buyer for signing the loyalty discount contract is less than the monopoly profit per buyer at $\bar{N}$, then it is less for any $N>\bar{N}$. Q.E.D.

Proposition 3 can be thought of as a comparative statics result for Proposition 2 (A). Part (i) says that there is some critical level of the entrant's costs such that the incumbent can induce at least one buyer to sign a loyalty discount contract if and only if the entrant's costs are greater than this critical level. In other words, if the entrant's cost advantage is too great, then loyalty discount contracts will be completely ineffective in limiting the entrant's market share and softening competition. Part (ii) says that there is some critical number of buyers such that the incumbent can induce at least one buyer to sign a loyalty discount contract if and only if the number of buyers exceeds this critical level. Since buyers impose a negative externality on each other when they sign a loyalty discount contract, each buyer internalizes less of the cost if there are more buyers. This makes loyalty discount contracts more effective in softening competition.

Before proceeding, let's pause to consider the robustness of our results to the buyer's option to breach the loyalty discount contract and pay damages. While we will not do a complete analysis here, it is worth noting that the result of the mixed strategy equilibrium will sometimes be that the incumbent's loyalty discounted price will be lower than the entrant's price. In those situations, there is no incentive for a buyer to breach. Even in situations in which the entrant's price is lower than the loyalty discounted price, the entrant's price will generally exceed its costs. This means that even if total surplus is higher with breach, the joint surplus of the incumbent and buyer may not be higher with breach. Lastly, note that even if a buyer does breach with positive probability, if the buyer must pay expectation damages, the incumbent can still earn the same level of profit. To see this, notice that the incumbent still has the option to charge $p^{m}+d$ to free buyers and $p^{m}$ to committed buyers. If those committed buyers breach, expectation damages will still ensure that the incumbent earns the monopoly profit on all of its committed buyers. Thus, any pricing equilibrium with breach must earn the incumbent a total profit (in expectation) equal to its monopoly profit from its committed buyers. Thus, the possibility of breach will not reduce the amount the incumbent will pay buyers to sign the loyalty discount contracts. Furthermore, it does not change the fact that a buyer externalizes some of its costs of signing the contract since signing the contract will induce the incumbent to price less aggressively even if it expects breach. This less aggressive pricing by the incumbent will still induce less aggressive pricing by the entrant, 
hence other buyers bear part of the social cost from one buyer signing the contract. So, while it is possible that breach could reduce the magnitude of this externality in some instances, it cannot eliminate it. So, at most, allowing buyer breach would reduce the situations where loyalty discount contracts are effective but would not eliminate it.

\subsection{Linear Demand Case}

With fully general demand functions, we have shown that with enough buyers and a small enough entrant cost advantage, the incumbent can use loyalty discounts to soften competition in any equilibrium. That said, at that level of generality, we cannot say much about how many buyers is enough or how small the entrant's cost advantage must be in order for loyalty discounts to be effective. To get some purchase on these issues, we now assume a linear demand function, $q(p)=1-p$. Notice that only the linear form is with loss of generality. Any linear demand function $a-b \tilde{p}$ is equivalent to a demand function of $1-p$ for $a$ units of the good priced in monetary unit that is $a / b$ of the original monetary unit. With linear demand it is possible to solve (8) explicitly for $p_{0}$. Doing so gives $p_{0}(\theta)=\left\{(1+c+2 d \theta)-\sqrt{(1-\theta)\left((1-c)^{2}-4 d \theta\right)}\right\} / 2$. This gives closed form expressions for both $F$ and $F_{e}$. Furthermore, the assumption of linear demand gives a closed form expression for consumer surplus for any given price, $s(p)=(1-p)^{2} / 2$, and for $I$ and $E$ 's monopoly price, $p^{m}=(1+c) / 2$ and $p_{e}^{m}=\left(1+c_{E}\right) / 2$ This means we can write expected consumer surplus for both committed and free buyers as a function of the number of committed buyers, $n$.

$$
\begin{aligned}
E s^{c}(n)= & \int_{p_{0}(n)}^{\left(1+c_{E}\right) / 2} \frac{1}{2}(1-p-d)^{2} \frac{\left(1+c_{E}-2 p\right)\left(1-p_{0}(n)\right)\left(p_{0}(n)-c_{E}\right)}{(1-p)^{2}\left(p-c_{E}\right)^{2}} d p+\frac{4\left(1-p_{0}(n)\right)\left(p_{0}(n)-c_{E}\right)}{\left(1-c_{E}\right)^{2}}(1-c)^{2} / 8 \\
E s^{f}(n)= & \int_{p_{0}(n)}^{\left(1+c_{E}\right) / 2} \frac{1}{2}(1-p)^{2} \frac{(n / N)(1+c-2(p-d))^{2}}{4(1-p)(p-c)(1-(n / N))} \frac{\left(1+c_{E}-2 p\right)\left(1-p_{0}(n)\right)\left(p_{0}(n)-c_{E}\right)}{(1-p)^{2}\left(p-c_{E}\right)^{2}} d p+ \\
& \int_{p_{0}(n)}^{\left(a+c_{E}\right) / 2} \frac{1}{2}(1-p)^{2} \frac{\left(1-p_{0}(n)\right)\left(p_{0}(n)-c_{E}\right)}{(1-p)\left(p-c_{E}\right)} \frac{(n / N)(1+c-2(p-d))\left((1-c)^{2}+2 d(1+c-2 p)\right)}{4(1-(n / N))(1-p)^{2}(p-c)^{2}} d p+ \\
& \frac{4\left(1-p_{0}(n)\right)\left(p_{0}(n)-c_{E}\right)}{\left(1-c_{E}\right)^{2}} \frac{(n / N)\left(c-c_{E}+2 d\right)}{(1-(n / N))\left(1-c_{E}\right)\left(1-2 c+c_{E}\right)}\left(1-c_{E}\right)^{2} / 8
\end{aligned}
$$

In these expressions, $p_{0}(n)$ is simply $p_{0}(\theta)$ with $\theta=n / N$. The first expression is the expected surplus for committed buyers when $n$ buyers will be committed. The integral term is the expected surplus when the incumbent prices between $p_{0}$ and $p_{e}^{m}$. For any given price, a committed buyer's 
surplus is $\frac{1}{2}(1-p-d)^{2}$ (because she gets the discount of $d$ off the price of $p$ offered to free buyers). The incumbent's probability density function in this region is $\frac{\left(1+c_{E}-2 p\right)\left(1-p_{0}(n)\right)\left(p_{0}(n)-c_{E}\right)}{(1-p)^{2}\left(p-c_{E}\right)^{2}}$. This can be computed simply by differentiating the incumbent's cumulative distribution function, equation (10), under the linear demand assumption. The incumbent will also charge committed buyers the monopoly price with probability $\frac{4\left(1-p_{0}(n)\right)\left(p_{0}(n)-c_{E}\right)}{\left(1-c_{E}\right)^{2}}$ and when that happens these buyers obtain a surplus of $(1-c)^{2} / 8$.

The second expression is the surplus for free buyers. This contains three terms. The first two reflect the expected surplus when neither $I$ nor $E$ charge their monopoly prices. The first is the expected surplus the buyer gets when buying from the incumbent, which occurs when the entrant's price is higher. For any given incumbent price $p$, the probability of this is $\frac{(n / N)(1+c-2(p-d))^{2}}{4(1-p)(p-c)(1-(n / N))}$. This is simply $1-F_{e}(p)$ with linear demand. The second term is the expected surplus the buyer gets when buying from the entrant, which occurs when the incumbent's price is higher. For any given entrant price $p$, the probability of this is $\frac{\left(1-p_{0}(n)\right)\left(p_{0}(n)-c_{E}\right)}{(1-p)\left(p-c_{E}\right)}$. Again, this is $1-F(p)$ with linear demand. The last part of this term is entrant's probability density function in this region with linear demand. The last term is the expected surplus if both $I$ and $E$ charge their monopoly prices. The first expressions are the probability that this occurs, the $\left(1-c_{E}\right)^{2} / 8$ expression is the buyer's surplus in this case (since the buyer buys from the entrant since $c_{E} \leq c$ ).

Unfortunately, it is not possible to get closed-form solutions for the integrals in (12) and (13) for arbitrary $c_{E}$ and $d$. Thus, we will proceed by numerical analysis. For any given set of parameter values, we can numerically calculate $E s^{c}(n+1)$ and $E s^{f}(n)$ to determine the loss in expected consumer surplus a buyer would receive from signing a loyalty discount contract with any given discount $d$ given that exactly $n$ other buyers will sign the contract. This gives the maximum amount the incumbent must pay to induce $n+1$ buyers to sign a loyalty discount contract with discount $d$. We call this the signing cost for $n$ signers. (It is the maximum amount since it may be cheaper to induce $n^{\prime}+1$ buyers to sign the contract for some $n^{\prime}>n$. Thus, if buyers expect $n^{\prime}$ other buyers to sign the contract, the incumbent may not need to pay as much.) We then numerically calculate the number of buyers, $n$, out of the total number of buyers, $N$, for which this signing cost reaches its maximum. This gives the maximum amount the incumbent would have to pay to induce all buyers to sign the loyalty discount contracts. ${ }^{11}$ We call this the maximum signing cost for any given discount, $d$. We then find, numerically, the discount, $d$, that minimizes this maximum signing cost.

\footnotetext{
${ }^{11}$ This is the maximum because then every buyer will sign for any belief about how many other buyers will sign.
} 
This procedure allows us to determine, for any given $c, c_{e}$, and $N$, the discount, $d$, that allows the firm to induce all buyers to sign a loyalty discount contract (given any beliefs about what other buyers will do) for the minimum up-front transfer, $t$. We can further determine how large $t$ has to be (this is simply the value of the maximum signing cost at the $d$ that minimizes this value) and whether it is less than the firm's profit from inducing the buyer to sign. This profit is simply $(1-c)^{2} / 4$, the monopoly profit per buyer. Using numerical root finding, we can also determine the maximum value of $c_{E}$ (for any given $c$ and $N$ ) for which the firm can induce all buyers to sign a loyalty discount contract in any equilibrium. ${ }^{12}$

We use this procedure to find this maximum value for $c_{E}$ for every integer value of $N$ between 3 and 20 (for $N=2$ we observed that it is not possible to induce one buyer to sign a loyalty discount if she believes the other buyer will not even if $c_{E}=c$ ) and for $c \in\{.1, .2, \ldots, .9\}$. Using this data, we then run a regression to generate a functional form for finding this maximum value for $c_{E}$ as a function of $N$ and $c$. We find that

$$
\begin{aligned}
\hat{c}_{E}= & 0.2080+0.7594 c+0.0361 c^{2}+0.0066 N-0.0102 c N+0.0040 c^{2} N \\
& -0.2408 \log [N]+0.2736 c \log [N]-0.0362 c^{2} \log [N]
\end{aligned}
$$

All of these coefficients have p-values of less than .01. The R-Squared for this regression is .99999.

It is probably easiest to get a sense of how effective loyalty discounts can be in this model to look at this expression graphically. Figure 1 uses (14) to plot $\hat{c}_{E} / c$ as a function of $c$ with $N=3,7$, and 20. With only three buyers, the incumbent can use loyalty discounts to completely foreclose buyers if the ratio of the entrant's cost to the incumbent's costs is above the thin solid line. So, if the incumbent's costs are less than about 0.04, then it can induce all buyers to sign a loyalty discount contract for any beliefs about what other buyers will do even if the entrant can produce at no cost at all. With only three buyers, however, the effectiveness of loyalty discounts falls quickly as the incumbent's cost increase. Once the incumbent's costs rise to 0.2 , loyalty discounts foreclose all buyers under any beliefs if and only if the entrant's costs are at least $85 \%$ of the incumbent's. If the incumbent's costs are 0.5 , this number rises to about $96 \%$. When the number of buyers rises

\footnotetext{
${ }^{12}$ While Proposition 3 tells us that the cost of obtaining the first signer is monotonically decreasing in $c_{e}$, we have not proved analytically that the cost of obtaining any number of signers is monotonically decreasing in $c_{e}$. That said, numerical analysis for the linear case has revealed no instances where the minimum (over $d$ ) of the maximum cost of inducing all buyers to sign is increasing in $c_{e}$. Furthermore, as we discuss in more detail below, except when the number of buyers is very large, this analysis also shows that the maximum cost occurs when buyers expect no other buyers to sign. This is precisely the case where Proposition 3 proves that the cost is monotonically decreasing in $c_{e}$.
} 
to seven, loyalty discounts become effective for a much larger range of costs. If the incumbent's costs are 0.15 , it can foreclose (again, for any beliefs) an entrant with zero costs. At costs of 0.5 , the incumbent can still foreclose the entrant under any set of buyer beliefs as long as the entrant's costs are no less than $79 \%$ of the incumbent's. Even at costs of 0.8, the incumbent can foreclose the entrant under any set of buyer beliefs as long as the entrant has no more than a $5 \%$ cost advantage. As the figure shows, with 20 buyers, foreclosure under any beliefs is even easier, especially if the incumbent's costs are not too large.

Figure 2 allows us to see more directly the effect of increasing the number of buyers by using (14) to plot $\hat{c}_{E} / c$ as a function of $N$ with $c=0.2,0.5$, and 0.8 . This figure shows that increasing the number of buyers allows the incumbent to foreclose the entrant under any set of buyer beliefs even as the entrant's cost advantage increases. The magnitude of the effect of increasing the number of buyers is diminishing as the number of buyer's increases and is more pronounced if the incumbent's costs are lower. Thus, if the incumbent's cost are 0.8, even with 20 buyers the entrant can only be foreclosed if it's cost advantage is less than 10\% (though, this is still a non-trivial cost advantage). On the other hand, if the incumbent's costs are 0.2 , it can foreclose an entrant under any set of buyer beliefs through loyalty discounts if it has at least 9 buyers even if the entrant's costs are zero.

It is worth noting that when there are 20 or fewer buyers, the maximum value for $c_{E}$ always occurred when buyers believed that no other buyer would sign the loyalty discount contract. That is, if the incumbent can profitably get one buyer to sign a loyalty discount contract then it can profitably get all buyers to do so. It is not the case, however, that inducing the first signer is always the most costly. For example, if $c_{E}$ is substantially above the maximum value necessary for there to exist an equilibrium in which no buyers sign the loyalty discount contract, then it can most costly for the incumbent to induce signing where buyers believe that some, but not all, other buyers will sign the loyalty contracts.

The results from the linear demand analysis give some insight into the likely importance of the possibility results in Proposition 2. Recall that part A of Proposition 2 tells us that if there are enough buyers and the entrant's cost advantage is small enough, there is no equilibrium in which at least one buyer does not sign a loyalty discount contract. Part B says that if there are enough buyers, there exists an equilibrium in which all buyers sign a loyalty discount contract. Our linear demand results make four main points that demonstrate that these possibility results likely have significant practical impact. These are summarized in the following remark.

Remark With linear demand and 20 or fewer buyers: 
1. If the incumbent can profitably induce one buyer to sign a loyalty discount contract then it can profitably create a unique equilibrium in which all buyers sign a loyalty discount contract.

2. If the entrant's cost advantage is small, it only takes three buyers to create this unique exclusionary equilibrium.

3. The larger the potential market (based on demand when price equals cost), the easier it is for the incumbent to create this unique exclusionary equilibrium.

4. The incumbent can create a unique exclusionary equilibrium for a substantial range of parameters even if the entrant has a non-trivial cost advantage. For example, if the entrant has no more than a $10 \%$ cost advantage, the incumbent can create a unique exclusionary equilibrium with three buyers if its costs are less than $28 \%$ of the choke price, with seven buyers if its costs are less than $68 \%$ of the choke price, and with 20 buyers if its costs are less than $80 \%$ of the choke price.

In our model, with zero costs of entry, entry is always efficient. Thus, our linear demand results show that there is substantial scope for an incumbent to profitably use loyalty discounts to inefficiently foreclose entry, reducing both productive efficiency and consumer surplus. Notice that this occurs, unlike in prior models of exclusive dealing, without any economies of scale and even with buyers with independent demands.

\section{Conclusion}

This article has shown that loyalty discounts that involve seller commitments to give loyal buyers lower prices than disloyal buyers can increase prices and/or block entry. Strikingly, this result is possible under any demand curve, even if the entrant is more efficient than the incumbent,and without any entry costs or economies of scale, and even if the buyers final consumers (or otherwise have independent demand). Further, unless the entrant cost advantage is sufficiently large, this equilibrium will always occur for a sufficient number of buyers. With linear demand, and an entrant cost advantage of less than $10 \%$, it will occur with as few as three buyers unless incumbent costs are more than $28 \%$ of the choke price. Not only are prices raised but a more efficient rival is kept off the market.

These results show that the intuition that loyalty discounts presumptively reduce prices is misplaced. Loyalty "discounts" are just the difference between loyal and disloyal pricing, and thus 
need not signify any true discount from the but-for prices that would have existed but for the loyalty discounts. In fact, this model shows that loyalty discounts encourage incumbents to raise prices above but for levels and discourage discounting to free buyers. These results also disprove the intuition that above-cost loyalty discounts cannot exclude an equally efficient rival. Here, abovecost loyalty discounts can exclude the rival even though the rival is in fact more efficient than the incumbent. Further, it can do so even though there are no economies of scale that might mean the rival has been relegated to a high cost portion of its cost curve. These results also disprove the claim that voluntary buyer agreement means the agreement must enhance the welfare of buyers.

A few limitations should, however, be stressed. First, we have assumed a market with only one potential rival. This can often be the case, especially in high-tech or pharmaceutical markets, but if there were multiple rivals with similar costs it is possible they would compete prices down to their costs. However, the same sort of analysis seems likely to apply to the extent only one entrant had a potential cost advantage and the other rivals had higher costs and merely provided a competitive fringe. Multiple rivals might also use loyalty discounts themselves, creating similar or even exacerbated market segmentation effects. ${ }^{13}$ But it remains for future work to extend the model here to cases involving multiple rivals or where multiple firms use loyalty discounts.

Second, we have assumed buyers make loyalty commitments that they always honor. The analysis would get more complicated if we considered the possibility that buyers could freely breach their commitments. However, as we have discussed above, if buyers must pay damages for breach of contract when they breach their loyalty commitments, then this would often deter breach, and even if it does not, it does not eliminate the ability of the incumbent to profitably use loyalty discount contracts to reduce competition. ${ }^{14}$ Moreover, as Elhauge (2009) has pointed out, there may be many reasons why the legal or extralegal penalties for breach exceed expectation damages.

Third, we have assumed loyalty discounts have no efficiencies. If they did, those might offset any adverse effects. It seems likely the present model can be extended to show how much of a cost reduction would be necessary to offset the anticompetitive effects, but that also remains a matter for future work.

\footnotetext{
${ }^{13}$ See Elhauge (2009) at pp. 195, 214-15 for a discussion of these issues.

${ }^{14}$ Note that Elhauge (2009) finds that under linear demand loyalty commitments will induce rivals to price sufficiently above cost that expectation damages will deter breach. He also finds that even without any buyer commitment at all, the seller commitment under loyalty discounts to price higher to buyers who did not agree to the loyalty condition will lead to higher prices under linear demand and equal costs.
} 


\section{References}

[1] Aghion, Philippe, and Patrick Bolton. 1987. "Contracts as a Barrier to Entry." American Economic Review, 77(3): 388-401.

[2] Bernheim, B. Douglas, and Michael D. Whinston. 1998. "Exclusive Dealing." Journal of Political Economy, 106(1): 64-103.

[3] Butz, David A. 1990. "Durable-Good Monopoly and Best-Price Provisions," American Economic Review 80: 1062-76.

[4] Cooper, Thomas E. 1986. "Most-Favored-Customer Pricing and Tacit Collusion," The RAND Journal of Economics 17: 377-388.

[5] Edlin, Aaron. 1997. "Do Guaranteed-Low-Price Policies Guarantee High Prices, and Can Antitrust Rise to the Challenge?", Harvard Law Review 111: 528-575.

[6] Elhauge, Einer. 2003. "Defining Better Monopolization Standards." Stanford Law Review 56: 253-344.

[7] Elhauge, Einer. 2008. United States Antitrust Law \& Economics. Foundation Press: New York.

[8] Elhauge, Einer. 2009. "How Loyalty Discounts Can Perversely Discourage Discounting," Journal of Competition Law \& Economics 5: 189-231.

[9] Farrell, Joseph. 2005. "Deconstructing Chicago on Exclusive Dealing," Antitrust Bulletin 50: 465-480 (2005).

[10] Fumagalli, Chiara, and Massimo Motta. 2006. "Exclusive Dealing and Entry, when Buyers Compete." American Economic Review, 96(3):785-95.

[11] Hovenkamp, Herbert. 2005. Antitrust Law Vol.. XI (2d ed.).

[12] Hovenkamp, Herbert. 2006. "Discounts and Exclusion." Utah Law Review, 2006: 841-861.

[13] Innes, Robert, and Richard J. Sexton. 1994. "Strategic Buyers and Exclusionary Contracts." American Economic Review, 84(3): 566-84.

[14] Kaplow, Louis \& Carl Shapiro. 2007. "Antitrust," in Handbook of Law \& Economics 2: 10731225 (eds. Polinsky \& Shavell). 
[15] Lambert, Thomas A.. 2005. "Evaluating Bundled Discounts." Minnesota Law Review, 89: $1688-1757$.

[16] Marx, Leslie M. \& Greg Shaffer. 2004. "Opportunism in Multilateral Vertical Contracting: Nondiscrimination, Exclusivity, and Uniformity: Comment," American Economic Review 94: 796-801.

[17] Mathewson, G. Frank, and Ralph A. Winter. 1987. "The Competitive Effects of Vertical Agreements: Comment." American Economic Review, 77(5): 1057-62.

[18] Neeman, Zvika. 1999. "The Freedom to Contract and the Free-Rider Problem." Journal of Law, Economics, and Organization, 15(3): 685-703.

[19] Rasmusen, Eric B., J. Mark Ramseyer, J., and John S, Wiley. 1991. "Naked Exclusion", American Economic Review, 81(5):1137-45.

[20] Schnitzer, Monika. 1994. "Dynamic duopoly with best-price clauses," The RAND Journal of Economics 25: 186-96.

[21] Segal, Ilya R., and Michael Whinston. 2000. "Naked Exclusion: Comment." American Economic Review, 90: 296-309.

[22] Simpson, John and Abraham L. Wickelgren. 2007. "Naked Exclusion, Efficient Breach, and Downstream Competition." American Economic Review, 97: 1305-1320.

[23] Spector, David. 2005. "Loyalty Rebates: An Assessment of Competition Concerns and a Proposed Structured Rule of Reason," Competition Policy International 1(2): 89-114 (Autumn).

[24] Tom, Willard K., David A. Balto \& Neil W. Averitt. 2000. "Anticompetitive Aspects of MarketShare Discounts and Other Incentives to Exclusive Dealing," Antitrust L.J. 67: 615.

[25] Whinston, Michael D. 2006. Lectures on Antitrust Economics (2006). 
Figure 1

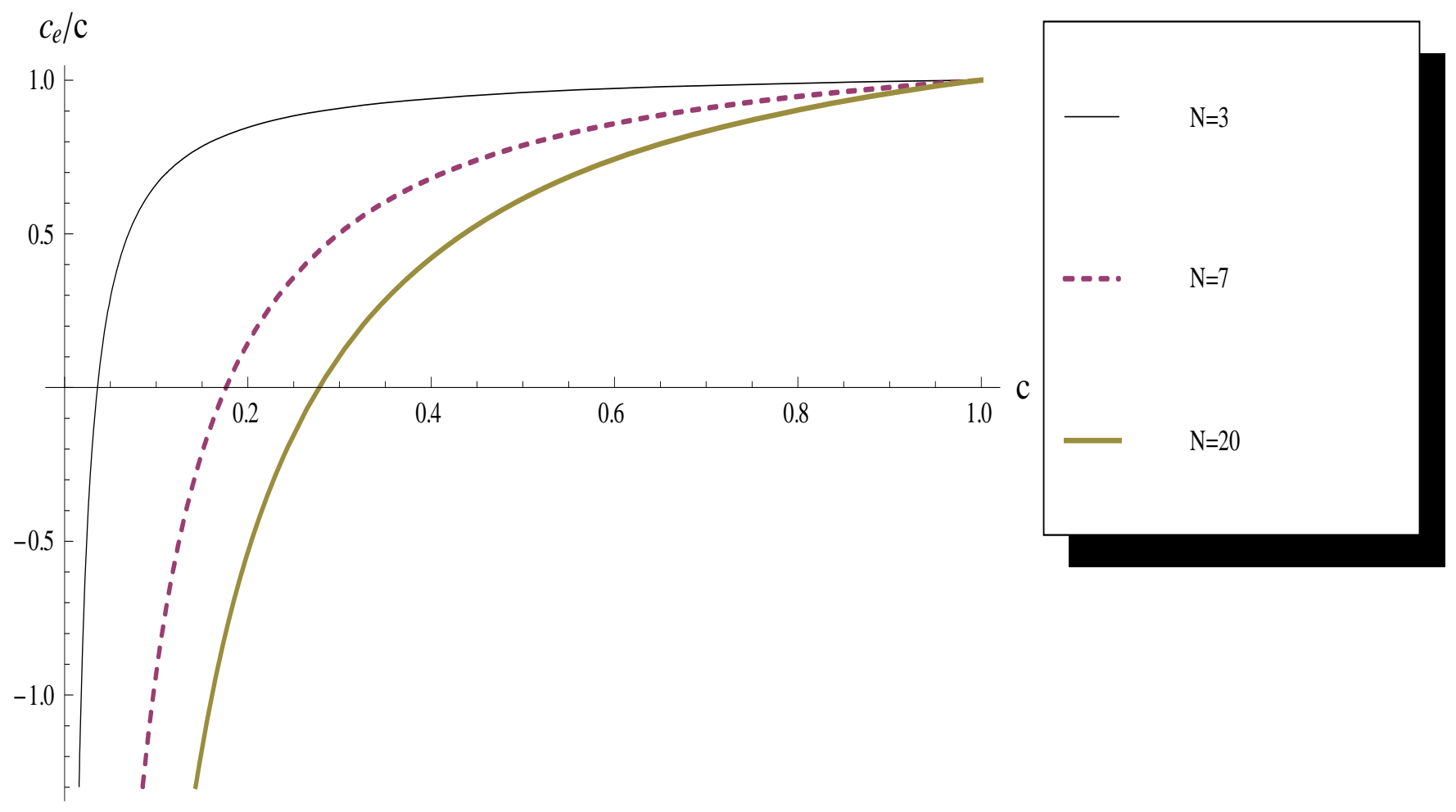

Figure 2

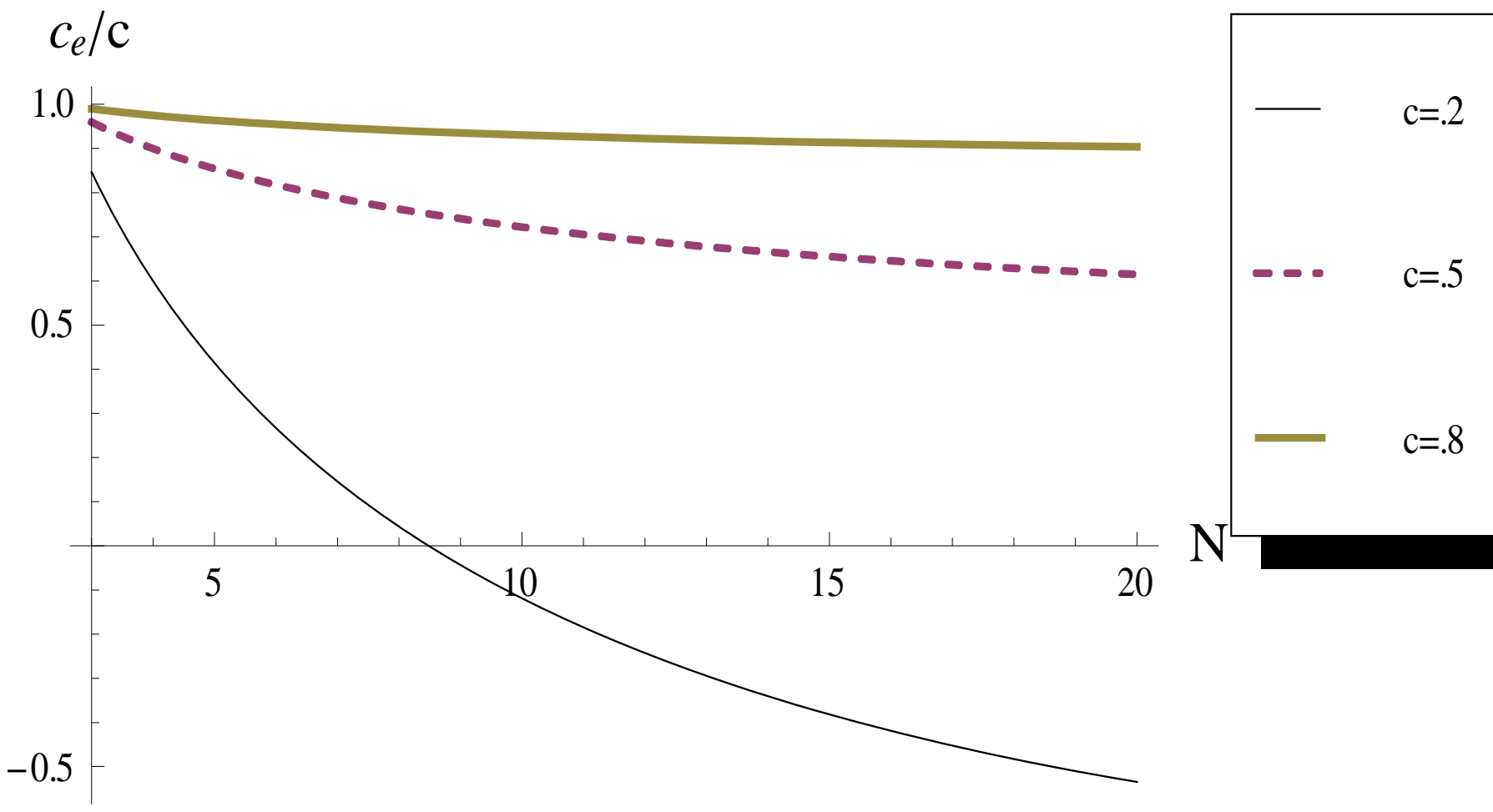

